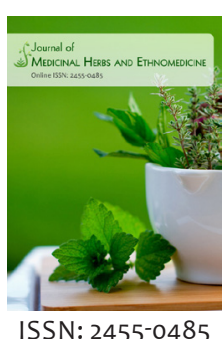

Received: June 25, 2020 Accepted: September 30, 2020 Published: February 03, 2021

*Corresponding author: Akeem Akinboro, Email: aakinboro@lautech. edu.ng

\section{Antigenotoxic potential of gel extract of Aloe vera against Sodium azide genotoxicity in Allium cepa cells}

\author{
Akeem Akinboro ${ }^{\text {**, Aisha Jimoh' }}$ \\ Department of Pure and Applied Biology, Ladoke Akintola University of Technology, Ogbomoso, P.M.B. 400o, \\ Oyo State, Nigeria
}

\begin{abstract}
Nowadays, the increasing rate of human exposure to various kinds of environmental mutagens has necessitated the search for natural antimutagens /antigenotoxic agents in natural products. In this study, Aloe vera gel extract was tested for its possible antigenotoxicity following the Allium cepa assay. Ten onions (Allium cepa) per dose were grown for 48 and 72 hours on gel extract of $A$. vera at $6.25 \%, 12.5 \%, 25.0 \%, 50.0 \%$ and $100.0 \%$ in combination with sodium azide $(0.05 \mathrm{mg} / \mathrm{ml})$ solution for microscopic and macroscopic evaluations, respectively. Distilled water and sodium azide were the negative and positive controls, respectively. The cell division in the root tips, and root growth in the exposed A. cepa were inhibited in a dose dependent manner by the mixture of $A$. vera and sodium azide. However, the mixture of absolute $(100.0 \%)$ dose and sodium azide completely arrested cell division and induced lower root length than that recorded for sodium azide alone. The genotoxicity of sodium azide was inversely reduced by the doses of $A$. vera except at $100.0 \%$. These results show that gel extract of $A$. vera possesses strong antigenotoxic/antimutagenic potency at lower dose range of $6.25 \%$ to $25.0 \%$ in $A$. cepa cells, however, its higher doses above $50.0 \%$ to $100.0 \%$ could be severely toxic when being considered for suppression of environmental mutagens' mutagenicity or genotoxicity. This suggests that gel extract of $A$. vera contains phytochemical(s) that can be useful in the development of anticancer drug.
\end{abstract}

KEYWORDS: Aloe vera; Allium cepa; Antimutagenicity; Mutagenicity; Sodium azide

\section{INTRODUCTION}

Protection of the genetic system in cellular organisms is an indispensable task to ensure normal biochemical and physiological functions. Antigenotoxicity is one of the ways to prevent assaults onto the genetic material of a living organism at both unicellular and multicellular levels. Chemical substances that prevent / inhibit alterations in the organizational structure of genetic element could have an application in the development of anticancer agents because they can prevent the very crucial initiation stage of cancer development. Natural products and compounds known with medicinal properties are receiving much attentions of scientific investigators today in an attempt to discover their possible new pharmacological properties and also validate their existing medicinal claims. Naturally occurring antigenotoxic agents found in major foods or food supplements are beneficial as they delay or inhibit cancer formation (Skrzypczak et al., 2015). Antimutagenic compounds prevent the genetic system of cells from damages through drugs, foods and their metabolites, as well as radiations (Akeem et al., 2011). Deaths from cancers have been projected to reach 11.4 million by the year 2030 (Loh et al., 2009). Environmental pollution and unhealthy lifestyle through nutrition and physical activities have been suggested to come with significant number of genotoxic factors related to development of cancer, diabetes and obesity. Aloe arborescens Miller and Aloe barbadenesis Miller also known as Aloe vera (Linn.) have been reported for their beneficial medicinal values including antitumoral, antidiabetic and immune boosting activities (Berti et al., 2016; Guo \& Mei, 2016).

Aloe vera originated from the warm, dry climates of Africa and belongs to the family Liliaeceae. It is readily adaptable and grows worldwide (Taiwo et al., 2005). The gel extracts of this plant as moisturizing cosmetics are topically applied on the skin by man to heal wound, and is consumed in health foods and beverages as laxative. It is also used to cure fever, burns, gastroenteritis, diabetes, inflammation, sexual diseases, infertility problems, cancer, and problems of the immune system. There are reports of antigenotoxic effects of gel extract of $A$. vera against benzo[a] pyrene - induced DNA damages, as an indirect acting mutagen that can cause adducts formation. Also, potentiality of $A$. vera gel extract in suppressing mutagenicity of ethyl methane sulphonate, a direct acting mutagen, following the Drosophila sex-linked recessive lethal test (SLRL) in 3-day old adults was

Copyright: $\odot$ The authors. This article is open access and licensed under the terms of the Creative Commons Attribution License (http://creativecommons.org/licenses/by/4.0/) which permits unrestricted, use, distribution and reproduction in any medium, or format for any purpose, even commercially provided the work is properly cited. Attribution - You must give appropriate credit, provide a link to the license, and indicate if changes were made. 
investigated (Snežana, 2007; Shamim et al., 2013; Słoczyńska et al., 2014). The immune stimulating effect of the plant was suggested as one of its mechanisms of suppressing cancer development. The whole leaf of Aloe vera contains $98.5 \%$ water and the remaining solid materials (leaf extract, gel and latex) contain more than 200 chemicals substances, of which over 75 of them are biologically active compounds such as vitamins, minerals, enzymes, polysaccharides, amino acids, phenolics and organic acids, anthraquinones, lignins and phytosterol which confer the aforementioned medicinal properties on the plant (Shamim et al., 2013; Guo \& Mei, 2016). Genotoxicity and antigenotoxicity of extract of $A$. vera were conducted using chromosome aberrations test in the bone marrow cells of rats, sister chromatids exchange, micronucleus and chromosomal aberrations in human lymphocytes, and the Ames Salmonella/ microsome test system (Anil et al., 2015). However, none of these reported tests adopted the Allium cepa root mitosis assay as it is being used to evaluate potency of gel extract of $A$. vera in suppressing genotoxicity of sodium azide, a direct acting mutagen, in this present study.

\section{MATERIALS AND METHODS}

\section{Preparation of Gel Extract}

Aloe vera plant weighing $5 \mathrm{~kg}$ was extracted by squeezing out gel extract from the leaves and this was preserved in the refrigerator at $4^{\circ} \mathrm{C}$ for antigenotoxic evaluation.

\section{Allium cepa Assay}

Onions were bought from Wazo market in Ogbomoso, Oyo state, Nigeria. They were sun dried for 1 week in order to facilitate their growth when planted for the antigenotoxicity evaluation. The outer scales of the dried onions were removed and the primordial root ring was carefully trimmed to remove dried old roots (Akinboro et al., 2017; Akwu et al., 2019). The absolute Aloe vera gel extract $(100.0 \%)$ was diluted with distilled water to prepare $6.25 \%, 12.5 \%, 25.0 \%, 50.0 \%$ doses. The positive and negative controls were sodium azide solution prepared at $0.05 \mathrm{mg} / \mathrm{ml}$ and distilled water, respectively. Ten onions per dose were placed in the solution of sodium azide at $0.05 \mathrm{mg} / \mathrm{ml}$ (a direct mutagen) inside a $100 \mathrm{ml}$ capacity glass beaker and placed in a cupboard for 24 hours. Sprouted onions after 24 hours of growth in the sodium azide solution were transferred into the doses of Aloe vera gel extract so as to continue root growth for another 24 hours (Akinboro et al.,
2011; Akinboro et al., 2016; Madić et al., 2019). After 48 hours, root tips from four onions from each dose were harvested with a scissors, fixed in Canoy's fixative (3:1 ethanol acetic acid, $\mathrm{v} / \mathrm{v}$ ) and kept at $4^{\circ} \mathrm{C}$ for slides preparation. The fixed root tips were hydrolyzed in 1NHCL for 10 minutes in a water-bath heated at $60^{\circ} \mathrm{C}$. The hydrolysed root tips were rinsed three times with distilled water. Two root tips were macerated on a glass slide and 2 drops of acetoorcein stain were added to the root tips smear on the slide and this was allowed to stand for 15 minutes. Further preparations of the slides were done as previously described (Akinboro \& Bakare, 2007; Çavuşoğlu et al., 2016; Priyanka et al., 2019. Five slides were observed for the stages of mitosis and chromosomal aberrations induced by each dose of $A$. vera gel extract in combination with sodium azide (Akinboro et al., 2012; Akinboro et al., 2014; Akinboro et al., 2016). The remaining six onions were suspended in freshly prepared Aloe vera gel extract for another 24 hour root growth. After 72 hours of root growth of onions, the root lengths of these onions were measured using a ruler in order to examine the effect of the mixture of Aloe vera gel extract and sodium azide on onions root growth.

\section{Statistical Analysis}

Obtained data were summarized to mean, standard deviation and percentage using descriptive statistics in the SPSS software (version 21.0). Means were separated with Duncan's multiple range test where significant difference was set at $\mathrm{p} \leq 0.05$.

\section{RESULTS}

Cytotoxicity of the mixture of gel extract of Aloe vera and sodium azide in Allium cepa root tip cells was dose dependent (Table 1$)$. Sodium azide $(0.05 \mathrm{mg} / \mathrm{ml})$, the positive control induced the least mitotic index value of $1.16 \%$, while the distilled water (negative control) recorded highest mitotic index value of $9.05 \%$. Aloe vera gel extract dose of $6.25 \%$, $12.5 \%, 25.0 \%, 50.0 \%, 100.0 \%$ in combination with sodium azide $(0.05 \mathrm{mg} / \mathrm{ml})$ produced mitotic index values $6.26 \%$, $4.76 \%, 3.45 \%, 3.10 \%$ and $0 \%$, respectively. The phase index was observed to have highest frequency of prophase in all the doses of Aloe vera gel extract and controls. Other dividing stages of mitosis were also observed at lower frequencies at all the selected doses except $100.0 \%$ that induced complete arrest of cell division. Toxicity of sodium azide to cell division in the root tips of onions was reduced by $56.35 \%$ at $6.25 \%$ dose, while $12.5 \%, 25.0 \%$ and $50.0 \%$ doses were able to reduce the mutagen's cytotoxicity by $39.78 \%, 25.30 \%$ and $21.44 \%$,

Table 1: Effects of mixture of gel extract of Aloe vera and sodium azide on mitosis in Allium cepa cells

\begin{tabular}{|c|c|c|c|c|c|c|c|}
\hline Dose (\%) & Prophase & Metaphase & Anaphase & Telophase & No of dividing cells & Mitotic index (\%) & Reduction of $\mathrm{NaN}_{3}$-cytotoxicity (\%) \\
\hline Negative control & 161 & 98 & 66 & 60 & 380 & 9.05 & - \\
\hline NaN3(+ ve control) & 18 & 12 & 11 & 7 & 49 & 1.16 & - \\
\hline 6.25 & 104 & 63 & 49 & 48 & 263 & 6.26 & 56.35 \\
\hline 12.5 & 77 & 40 & 34 & 48 & 200 & 4.76 & 39.78 \\
\hline 25.0 & 61 & 34 & 26 & 28 & 145 & 3.45 & 25.30 \\
\hline 50.0 & 57 & 30 & 22 & 21 & 130 & 3.10 & 21.44 \\
\hline 100.0 & 0 & 0 & 0 & 0 & 0 & 0 & N.C \\
\hline
\end{tabular}

N.C.: not calculable 
respectively. However, it was not possible to calculate the degree of reduction of sodium azide - induced cytotoxicity by the Aloe vera gel extract at $100.0 \%$ because there was no dividing cells at this dose.

The genotoxic effect of sodium azide on the cell of Allium cepa was evident as different forms of chromosomal aberrations such as stickiness, chromosome bridge, colchicine mitosis, vagrant chromosome, nuclear abnormality, disturbed spindle and chromosome break were induced at higher frequencies by the direct mutagen (sodium azide) than those induced by the combination of sodium azide and Aloe vera gel extract. The percentage chromosomal aberration recorded with sodium azide was the highest at $0.55 \%$, others were $0.29 \%, 0.31 \%, 0.31 \%$ and $0.41 \%$ recorded at $6.25 \%, 12.5 \%, 25.0 \%$ and $50.0 \%$ doses. However, no chromosomal aberrations were recorded at $100.0 \%$ of A. vera gel extract in combination with sodium azide because no cell was observed to be dividing. Genotoxicity of sodium azide was suppressed by $47.27 \%$ at the least dose of $6.25 \%$ of the gel extract of Aloe vera. At each of 12.5 and $25.0 \%$ doses, $43.64 \%$ suppression was recorded, while $50.0 \%$ dose suppressed sodium azide genotoxicity by $25.46 \%$. However, there was a complete inhibition of cells division at $100.0 \%$ gel extract dose in combination with sodium azide making the calculation of extent of sodium azide genotoxicity reduction impossible at this dose (Table 2).

C-bridge: chromosome bridge, C- mitosis: chromosome mitosis, vagrant C: vagrant chromosome, N.A.: nuclear abnormalities, D.S.: disturbed spindle, C.B.: chromosome break.

The root growth toxicity of sodium azide to A. cepa was suppressed by Aloe vera gel extract in an inversely proportional to the selected doses except $100.0 \%$. The highest suppression of $\mathrm{NaN}_{3}$ - toxicity was recorded at $6.25 \%$ dose resulting to
$64.24 \%$. At $12.5 \%, 25.0 \%$ and $50.0 \%$ doses, the suppression was $35.76 \%, 10.07 \%$ and $0.69 \%$, respectively. There was a synergistic reaction between sodium azide and gel extract at $100.0 \%$ dose resulting to an increased toxicity to the root growth by $-0.69 \%$ rather than to suppress it. The root growth obtained with the distilled water was significantly different $(\mathrm{p} \leq 0.05)$ from that of the sodium azide and those of all the tested doses of Aloe vera gel extract (Table 3).

\section{DISCUSSION}

Toxicity of the mixture of the gel extract of Aloe vera and sodium azide to cell division in the root tips of Allium cepa in a dose dependent manner suggests that there was a synergistic inhibition of cell division in $A$. cepa. However, mixture of the absolute gel extract of $A$. vera and sodium azide used in this study was able to arrest mitosis completely, suggesting that each of the two major reactants (gel extract and sodium azide) had cytotoxic effects on mitosis in the test organism. Similar mitotic inhibition caused by Aloe vera leaf gel extract alone and mixture of Aloe vera leaf extract and sodium chloride in A. cepa was reported (İlbaş et al., 2012; Çavuşoğlu et al., 2016). Phytochemicals in the gel extract of $A$. vera and sodium azide itself could have prevented synthesis of DNA and nucleoprotein by blocking events at G1, S phases and G2 of the cell cycle from taking place thereby preventing cells from entering mitotic phase (Priyanka et al., 2019). Anthraquinones, aloin, barbalion, anthranol, cinnamic acid, acemannan, aloe emodin, aloetic acid, chysalodin, chrysophanic acid, resistanol, cyclooxygenase, bradykininase (enzymes), vitamins (tocopherol, vitamin $\mathrm{C}$ ), saccharides, amino acids, carotenoids, falvonoids, tannins, superoxide dismutase and glutathione enzymes are the most common phytochemicals in the leaf and gel extracts of $A$. vera (Kayraldiz et al., 2010; Sapkota et al., 2019; Liu et al., 2019; Kim et al., 2020). Aloe emodin is well known for its cytotoxic

Table 2: Chromosomal aberrations induced by mixture of Aloe vera extract and sodium azide in Allium cepa cells

\begin{tabular}{|c|c|c|c|c|c|c|c|c|c|c|}
\hline Dose (\%) & Stickiness & C- bridge & C-mitosis & Vagrant C & N. A. & D.S. & C.B. & Total aberration & $\%$ aberrant cells & $\begin{array}{c}\% \text { reduction of } \mathrm{NaN}_{3} \\
\text { genotoxicity }\end{array}$ \\
\hline Distilled water & 0 & 0 & 0 & 0 & 0 & 0 & 0 & 0 & 0 & 0 \\
\hline $\mathrm{NaN}_{3}$ (sodium azide) & 1 & 5 & 5 & 0 & 3 & 4 & 5 & 23 & 0.55 & 0 \\
\hline 6.25 & 2 & 2 & 1 & 2 & 1 & 1 & 3 & 12 & 0.29 & 47.27 \\
\hline 12.5 & 3 & 4 & 1 & 1 & 0 & 2 & 2 & 13 & 0.31 & 43.64 \\
\hline 25.0 & 2 & 3 & 0 & 1 & 0 & 3 & 4 & 13 & 0.31 & 43.64 \\
\hline 50.0 & 3 & 4 & 2 & 2 & 0 & 2 & 4 & 17 & 0.41 & 25.46 \\
\hline 100.0 & - & - & - & - & - & - & - & - & - & - \\
\hline
\end{tabular}

C-bridge: chromosome bridge, C- mitosis: chromosome mitosis, vagrant C: vagrant chromosome, N.A.: nuclear abnormalities, D.S.: disturbed spindle, C.B.: chromosome break.

Table 3: Effectiveness of Aloe vera gel extract in reducing sodium azide - induced root growth toxicity in Allium cepa

\begin{tabular}{lcccc}
\hline Dose (\%) & Mean Root length $(\mathrm{cm})$ & \% root growth & \% root growth inhibition & Reduction of NaN $_{3}-$ root growth toxicity \\
\hline Distilled water & $2.88 \pm 0.85^{\mathrm{a}}$ & 100.00 & 0.00 & - \\
NaN $_{3}$ (sodium azide) & $0.21 \pm 0.05^{\mathrm{d}}$ & 7.29 & 92.71 & - \\
6.25 & $2.06 \pm 0.55^{\mathrm{b}}$ & 71.53 & 28.47 & 64.24 \\
12.5 & $1.24 \pm 0.56^{\mathrm{c}}$ & 43.06 & 56.94 & 35.76 \\
25.0 & $0.50 \pm 0.16^{\mathrm{d}}$ & 17.36 & 82.64 & 10.07 \\
50.0 & $0.23 \pm 0.14^{\mathrm{d}}$ & 7.99 & 92.01 & 0.69 \\
100.0 & $0.19 \pm 0.07^{\mathrm{d}}$ & 6.60 & 93.40 & -0.69 \\
\hline
\end{tabular}

Values with different superscript alphabets are significantly different at $p<0.05$. 
effect, and ability to induce apoptosis in various cells (Cosmetic Ingredient Review Expert Panel, 2007). The higher frequency of dividing cells at prophase induced at the selected doses of gel extract of $A$. vera and controls could be due to the fact that at the beginning of mitosis large number of cells enter prophase after leaving interphase. Induction of higher mitotic index (MI) values by the mixture of gel extract and sodium azide than the sodium azide alone indicates reduction of cytotoxic effect of sodium azide on mitosis in the root tips of $A$. cepa. This effect of the gel extract of $A$. vera to suppress cytotoxic effect of sodium azide was corroborated by the results of longer root lengths produced by the mixture of gel extract of $A$. vera and sodium azide at the tested doses than the root length caused by sodium azide alone. These results are in accordance with the previously obtained results (Çavuşoğlu et al., 2016). It was revealed that the gel extract at its absolute dose in combination with sodium azide was severely toxic to both cell division in the root tips and root growth in $A$. cepa as all cells were at interphase and the root length obtained from the mixture of $100 \%$ gel extract and sodium azide was lower than that of sodium azide alone. This is an indication that gel extract of $A$. vera can be cytotoxic at a high dose.

Mutagenicity of sodium azide is well established in Escherichia coli, fungi, higher plants (such as rice, barley and corn), mammalian cells (National Toxicology Program, 1999). Sodium azide is a direct acting mutagen that reacts directly with a DNA molecule to cause damage, unlike indirect acting mutagens whose metabolites cause DNA damages. The lower frequency of chromosomal aberrations caused by the mixture of gel extract of $A$. vera and sodium azide compared with the aberrations induced by sodium azide alone implies antigenotoxicity of gel extract of $A$. vera. Previously, antigenotoxicity of gel extract of $A$. vera against genotoxicity of a direct mutagen (ethylmethanesulphonate) induced in Drosophila melanogaster following the Drosophila sex linked recessive lethal test was reported (Snežana, 2007). Ogunjobi et al. (2007) also reported antimutagenic and anticarcinogenic activity of aqueous garlic extract and $A$. vera gel extract inhibiting acridine dye - inducing mutation in the tester strain Escherichia coli WP2 uvrA. In the present study, our results have also confirmed antigenotoxic potency of $A$. vera gel extract against sodium azide. The observed inhibition of sodium azide-induced genotoxicity in $A$. cepa cells by the gel extract of $A$. vera could be caused by natural antioxidants such as polyphenols, indoles, polysaccharides, and alkaloids in the plant. Antigenotoxic effect of acemannan against benzo [a] pyrene-induced DNA adducts formation in rats by increasing activity of glutathione S-transferase (Liu et al., 2019). Antioxidant activities of acemannan in terms of free radical scavenging, chelating, reduction of iron capabilities have been reported. Relationship between antioxidant activity of shikonin, acetylshikonin and Arnebia euchroma callus extracts and suppression of genotoxic effect of 4-nitroquinoline oxide and 2-aminoanthracene was reported (Skrzypczak et al., 2015). Polyphenolic compound like curcumin in its modified and unmodified forms were found to attenuate the cisplatin-induced DNA damage (Mendonça et al., 2015). Other mechanisms of inhibition of genotoxic effect of mutagens are inhibition of genotoxic effect, inhibition of cell proliferation, and modulation of signal transduction (Berti et al., 2016). Contrarily, Anil et al. (2015) reported that A. vera leaf extract did not decrease genotoxicity of urethane in the bone marrow cells of rats and mytomycin - C induced genotoxicity in human lymphocytes. This could be due to differences in the mutagens used and the kind of assays adopted for the evaluation.

\section{CONCLUSION}

This study has revealed that gel extract of $A$. vera is capable of suppressing genotoxicity of sodium azide in the root tip cells of A. cepa in a dose dependent manner. However, the gel extract can be cytotoxic at a dose above $50 \%$. Our results have further confirmed the antigenotoxicity potential of $A$. vera gel extract against sodium azide, a different direct acting mutagen which was used in this study for the first time following the $A$. cepa root mitosis assay.

\section{CONFLICT OF INTEREST}

There is no conflict of interest declared.

\section{REFERENCES}

Akeem, A., Mohamed, K. B., Asmawi, M. Z., \& Sofiman, O. A. (2011) Mutagenic and antimutagenic potentials of fruit juices of five medicinal plants in Allium cepa L.: Possible influence of DPPH free radical scavengers. African Journal of Biotechnology, 10(50), 1024810257. https://doi.org/10.5897/AJB11.694

Akinboro, A., \& Bakare, A. A. (2007). Cytotoxic and genotoxic effects of aqueous extracts of five medicinal plants on Allium cepa Linn. Journal of Ethnopharmacology, 112(3), 470-475. https://doi.org/10.1016/j. jep.2007.04.014

Akinboro, A., Adedosu, O. T., Famurewa, F. O., Olowe, T., \& Oyewole, O. O. (2017). Antioxidant, proximate and cyto-genotoxic evaluation of antityphoid fever herbal recipe in Allium cepa cells. Global Journal of Bio-Science and Biotechnology, 6(1), 24-29.

Akinboro, A., Baharudeen, I., \& Mohamed, K. (2016). Evaluation of cytogenotoxic and antimutagenic potency of water extract of Centella asiatica Linn. using the Allium cepa assay. International Food Research Journal, 23(6), 2449-2452.

Akinboro, A., Kamaruzaman, B. M., Asmawi, M. Z., \& Yekeen T. A. (2014). Antimutagenic effects of aqueous fraction of Myristica fragrans (Houtt.) leaves on Salmonella typhimurium and Mus musculus. Acta Biochimica Polonica, 61, 779-785. https://doi.org/10.18388/ abp.2014_1846

Akinboro, A., Mohamed, K. B., Asmawi, M. Z., Othman, A. S., Ying, T. H., \& Maidin, S. M. (2012). Mutagenic and antimutagenic assessment of methanol leaf extract of Myristica fragrans (Houtt.) using in vitro and in vivo genetic assays. Drug and chemical toxicology, 35(4), 412-422. https://doi.org/10.3109/01480545.2011.638300

Akinboro, A., Mohamed, K. B., Asmawi, M. Z., Sulaiman, S. F., \& Sofiman, O. A. (2011). Antioxidants in aqueous extract of Myristica fragrans (Houtt.) suppress mitosis and cyclophosphamide-induced chromosomal aberrations in Allium cepa L. cells. Journal of Zhejiang University-ScienceB, 12(11), 915-922. https://doi.org/10.1631/jzus. B1000315

Akwu, N. A., Naidoo, Y., \& Singh, M. (2019). Cytogenotoxic and biological evaluation of the aqueous extracts of Grewia lasiocarpa: An Allium cepa assay. South African Journal of Botany, 125:371-380. https:// doi.org/10.1016/j.sajb.2019.08.009

Anil, S., Ankit, A., \& Nagalakshmi, N. C. (2015). Aloe vera as traditional medicinal plant: a review on its active constituents, biological and therapeutic effects. World Journal of Pharmaceutical Research, 4(6), 2146-2161.

Berti, A. P., Palioto, G. F., \& Rocha, C. L. M. S. C. (2016). Antimutagenicity and antigenotoxicity of Aloe arborescens Miller and Aloe barbadensis 
Miller in Aspergillus nidulans and Wistar rats. Genetics and Molecular Research, 15(3), gmr8522. https://doi.org/10.4238/gmr.15038522

Çavuşoğlu, D., Tabur, S., \& Çavuşoğlu, K. (2016). The Effects of Aloe vera L. Leaf Extract on Some Physiological and Cytogenetical Parameters in Allium cepa L. Seeds Germinated under salt stress. Cytologia, 81(1), 103-110. https://doi.org/10.1508/cytologia.81.103

Cosmetic Ingredient Review Expert Panel (2007). Final report on the safety assessment of Aloe andongensis Extract, Aloe andongensis leaf juice, Aloe arborescens leaf extract, Aloe arborescens leaf juice, Aloe arborescens leaf protoplasts, Aloe barbadensis flower extract, Aloe barbadensis leaf, Aloe barbadensis leaf extract, Aloe barbadensis leaf juice, Aloe barbadensis leaf polysaccharides, Aloe barbadensis leaf water, Aloe ferox leaf extract, Aloe ferox leaf juice, and Aloe ferox leaf juice extract. International journal of toxicology, 26 Suppl 2, 1-50. https://doi.org/10.1080/10915810701351186

Guo, X., \& Mei, N. (2016). Aloe vera: A review of toxicity and adverse clinical effects. Journal of Environmental Science and Health. Part C, Environmental Carcinogenesis \& Ecotoxicology Reviews, 34(2), 77-96. https://doi.org/10.1080/10590501.2016.1166826

İlbaş, A. I., Gonen, U., Yilmaz, S., \& Dadandi, M. Y. (2012). Cytotoxicity of Aloe vera gel extracts on Allium cepa root tip cells. Turkish Journal of Botany, 36, 263-268. https://doi.org/10.3906/bot-1102-5

Kayraldiz, A., Kocaman, A. Y., Rencuzoğullari, E., İstifli, E. S., İla, H. B., Topaktaş, M., \& Dağlioğlu, Y. K. (2010). The genotoxic and antigenotoxic effects of Aloe vera leaf extract in vivo and in vitro. Turkish Journal of Biology, 34, 235-246. https://doi.org/10.3906/ biy-0812-27

Kim, J. H., Cho, C. W., Lee, J. I., Vinh, L. B., Kim, K. T., \& Cho, I. S. (2020). An investigation of the inhibitory mechanism of $\alpha$-glucosidase by chysalodin from Aloe vera. International Journal of Biological Macromolecules, 147, 314-318.

Kumar, S., Yadav, A., Yadav, M., \& Yadav, J. P. (2017). Effect of climate change on phytochemical diversity, total phenolic content and in vitro antioxidant activity of Aloe vera (L.) Burm.f. BMC Research Notes, 10(1), 60. https://doi.org/10.1186/s13104-017-2385-3

Liu, C., Cui, Y., Pi, F., Cheng, Y., Guo, Y., \& Qian, H. (2019). Extraction, Purification, Structural Characteristics, Biological Activities and Pharmacological Applications of Acemannan, a Polysaccharide from Aloe vera: A Review. Molecules, 24(8), 1554. https://doi.org/10.3390/ molecules24081554

Loh, D. S., Er, H. M., \& Chen, Y. S. (2009). Mutagenic and antimutagenic activities of aqueous and methanol extracts of Euphorbia hirta. Journal of ethnopharmacology, 126(3), 406-414. https://doi. org/10.1016/j.jep.2009.09.025

Madić, V., Stojanović-Radić, Z., Jušković, M., Jugović, D., Popović, A. Ž, \& Vasiljević, P. (2019). Genotoxic and antigenotoxic potential of herbal mixture and five medicinal plants used in ethnopharmacology. South African Journal of Botany, 125, 290-297. https://doi.org/10.1016/j. sajb.2019.07.043

Mendonça, L. M., Machado, C., Teixeira, C. C., Freitas, L. A., Bianchi, M. L., \& Antunes, L. M. (2015). Comparative study of curcumin and curcumin formulated in a solid dispersion: Evaluation of their antigenotoxic effects. Genetics and molecular biology, 38(4), 490-498. https://doi. org/10.1590/S1415-475738420150046

National Toxicology Program (1999). Toxicology and carcinogenesis studies of sodium azide (Cas no: 26628-228) in F344/N rats (Gavage studies). Technical Report Series. No 389.

Ogunjobi, A. A., Fagade, O. E., David, O. O. (2007). Antimutagenic and potential anticarcinogenic activities of aloe-vera gel and aqueous garlic extract in the bacterial reverse mutation test (Ames Assay). African Journal of Biomedical Research, 10, $275-278$.

Priyanka, Mohanka, R., Kumari, P., \& Kumar, B. (2019). Cytotoxicity evaluation of aqueous extracts of medicinal plants on Allium cepa $\mathrm{L}$. Journal of Biotechnology and Biochemistry, 5(2), 35-49. https://doi. org/10.9790/264X-0502013549

Sapkota, M., Shrestha, S. K., Yang, M., Park, Y. R., \& Soh, Y. (2019). Aloeemodin inhibits osteogenic differentiation and calcification of mouse vascular smooth muscle cells. European Journal of Pharmacology, 865, 172772. https://doi.org/10.1016/j.ejphar.2019.172772

Shamim, H., Mamun-Or-Rashid, A. N. M., Towfique, N., M., \& Monokesh, K. S. (2013). A review on ethnopharmacological potential of Aloe vera L. Journal of Intercultural Ethnopharmacology, 2(2):113120. https://doi.org/10.5455/jice.20130612035300

Skrzypczak, A., Przystupa, N., Zgadzaj, A., Parzonko, A., SykłowskaBaranek, K., Paradowska, K., \& Nałęcz-Jawecki, G. (2015). Antigenotoxic, anti-photogenotoxic and antioxidant activities of natural naphthoquinone shikonin and acetylshikonin and Arnebia euchroma callus extracts evaluated by the umu-test and EPR method. Toxicology in Vitro 30,(1 Pt B), 364-372. https://doi. org/10.1016/j.tiv.2015.09.029

Słoczyńska, K., Powroźnik, B., Pękala, E., \& Waszkielewicz, A. M. (2014). Antimutagenic compounds and their possible mechanisms of action. Journal of Applied Genetics, 55(2), 273-285. https://doi.org/10.1007/ s13353-014-0198-9

Snežana, S. (2007). Anti-genotoxic effect of Aloe vera gel on the mutagenic action of ethyl methanesulfonate. Archives of Biological Sciences, 59(3), 223-226. https://doi.org/10.2298/ABS0703223S

Taiwo, V. O., Olukunle, O. A., Ozor, I. C., \& Oyejobi, A. T.(2005). Consumption of Aqueous Extract of Raw Aloe Vera Leaves: Histopathological and Biochemical Studies in Rat and Tilapia. African Journal of Biomedical Research, 8, $169-178$. 